\title{
Stimulation of cyclic AMP production in human alveolar macrophages induced by inflammatory mediators and $\beta$-sympathicomimetics
}

\author{
Fred D. Beusenberg a , Jan G.C. Van Amsterdam ${ }^{a}$, Henk C. Hoogsteden ${ }^{\text {b }}$, Paul R.M. Hekking ${ }^{\text {c }}$, \\ Jan W. Brouwers ${ }^{\mathrm{d}}$, Hans P. Schermers ${ }^{\mathrm{d}}$ and Iván L. Bonta ${ }^{\text {a }}$ \\ a Department of Pharmacology, Faculty of Medicine and Health Sciences, Erasmus University, Rotterdam, Netherlands, \\ ${ }^{b}$ Department of Pulmonology, Dijkzigt University Hospitah Rotterdam, Netherlands, ' Department of Pulmonology, Haven Hospital, \\ Rotterdam, Netherlands, and ${ }^{d}$ Department of Pulmonology, St. Clara Hospital, Rotterdam, Netherlands
}

Received 21 January 1992, accepted 11 February 1992

\begin{abstract}
We have investigated the effects of inflammatory mediators and $\beta$-adrenoceptor agonists on the adenylyl cyclase responsiveness in alveolar macrophages from control subjects, patients suffering from chronic obstructive pulmonary disease (COPD) and asthmatics. Basal cyclic AMP (cAMP) levels in alveolar macrophages from COPD patients were significantly elevated (plus $42 \%$ ) as compared to controls. In addition, the adenylyl cyclase responsiveness to prostaglandin $\mathrm{E}_{2}$, histamine and the $\beta$-adrenoceptor agonist salbutamol was significantly impaired in alveolar macrophages from COPD patients and asthmatics. The lipid mediator platelet activating factor showed no effect on cAMP production in all three alveolar macrophage populations. Furthermore, the cAMP-enhancing effects of isoprenaline, salbutamol and histamine appeared to be mediated via $\beta_{2}$-adrenoceptors and histamine $\mathrm{H}_{2}$-receptor subtypes respectively. Taken together, these data suggest an intrinsic desensitization phenomenon in alveolar macrophages from COPD patients and asthmatics.
\end{abstract}

Alveolar macrophages; cAMP; Chronic obstructive pulmonary disease; Asthma; Adenylyl cyclase; Inflammatory mediators; $\beta$-Adrenoceptor agonists

\section{Introduction}

Pulmonary inflammation is incontrovertibly associated with chronic obstructive pulmonary disease (COPD) and asthma (Chung, 1986). Within the complex pathophysiological processes, alveolar macrophages exert a predominant role. Firstly, these cells act as scavengers in the first line of host defense by means of phagocytosis and related features like the production and release of reactive oxygen radicals and lysozomal enzymes (Fels and Cohn, 1986; Takemura and Werb, 1984). Secondly, alveolar macrophages retain a large potency to modulate the activity of other pulmonary cells via the release of inflammatory mediators like prostaglandins, leukotrienes and platelet activating factor (Morley et al., 1979; Arnoux et al., 1980; Fels et

Correspondence to: F.D. Beusenberg, Department of Pharmacology, Faculty of Medicine and Health Sciences, Erasmus University, P.O. Box 1738, 3000 DR Rotterdam, Netherlands. Tel. (31) 10-4087530, Fax (31) 10-4636839. al., 1982; MacDermot et al., 1984; Martin et al., 1984) and cytokines like interleukin-1 (IL-1) and tumor necrosis factor- $\alpha$ (TNF- $\alpha$ ) (reviewed by Sibille and Reynolds, 1989; Kelley, 1990).

With respect to functional activity between alveolar macrophages from controls, COPD patients and asthmatics, several conflicting results have been reported. Thus, eicosanoid release from alveolar macrophages of asthmatics and COPD patients has been shown to be impaired (Godard et al., 1982), unaltered (Balter et al., 1988) or even enhanced (Damon et al., 1989; Chavis et al., 1991). Furthermore, the release of platelet activating factor (PAF), oxygen radicals and $\beta$-glucuronidase appears to be enhanced in alveolar macrophages from asthmatics (Tonnel et al., 1986; Arnoux et al., 1987; Cluzel et al., 1987).

Pulmonary mediators and other substances like hormones and drugs interact with cells via specific surface receptors coupled to transmembrane signalling systems which produce several second messengers (reviewed by Barnes, 1987). Functional activity of alveolar macrophages (and cells in general) is largely associated 
with intracellular levels of cyclic AMP (cAMP), a second messenger produced by the action of adenylyl cyclase. In general, high levels of cAMP coincide with down-regulation of functional activity (Bonta and Parnham, 1982).

Though the effects of inflammatory mediators on general aspects of pulmonary inflammation have been clearly described, reports on their effects on alveolar macrophages remain scarce. Histamine, leukotrienes and PAF have potent bronchoconstrictive actions, stimulate mucus secretion and exert strong chemotactic potency for inflammatory cells (Goetzl and Pickett, 1981; Hannah et al., 1981; Finney et al., 1985; Wardlaw et al., 1986; Persson, 1988). Prostaglandins of the E-type have mainly bronchodilating properties (Gardiner, 1975). To further investigate the role of mediators in pulmonary inflammation, we performed studies on the effects of histamine, prostaglandin $\mathrm{E}_{2}\left(\mathrm{PGE}_{2}\right)$, prostacyclin ( $\mathrm{PGI}_{2}$ ) and PAF on adenylyl cyclase responsiveness in human alveolar macrophages from controls, COPD patients and asthmatics. In addition, the effects of the $\beta$-adrenoceptor agonists isoprenaline and salbutamol (frequently used as anti-asthmatic drugs) on adenylyl cyclase responsiveness were determined as well.

\section{Materials and methods}

\subsection{Subjects}

Smoking female volunteers ( $>5$ pack years, age 23-37 years, mean age 30 years) were studied. None of the subjects had a history of pulmonary disorders or received any medication 2 months prior to the study. Informed consent for bronchoalveolar lavage (BAL) was obtained. BAL was performed under general anesthesia using a fiber optic bronchoscope. Four subsequent volumes of $50 \mathrm{ml}$ sterile saline were instilled into a subsegmental bronchus of the right middle lobe, followed by gentle aspiration. The obtained BAL fluids were kept on ice until further isolation of alveolar macrophages.

\subsection{Patients}

The study included 12 COPD patients (seven female, five male, ages 24-75 years, mean age 51 years) and two non-atopic asthmatics (female, ages 31 and 37 years). Diagnosis of COPD patients (chronic bronchitis, $n=6$; bronchial emphysema, $n=6$ ) was based on a history of clinical symptoms, chest X-ray and pulmonary function tests. Mean forced expiratory volume $\left(\mathrm{FEV}_{1}\right)$ was $72 \pm 6.9 \%$ and mean forced expiratory vital capacity (FVC) was $83 \pm 4.0 \%$ (percentage of predicted value). All of them were tobacco smokers ( $>13$ pack years), three received $\beta$-sympathicomimetics and one corticosteroids. Bronchial asthma was diagnosed on the basis of clinical history, severity of airway obstruction $\left(\mathrm{FEV}_{1}\right.$ less than $70 \%$ of predicted value) and partial reversibility after inhalation of $\beta$-adrenoceptor agonists.

\subsection{Isolation of alveolar macrophages}

BAL fluids were filtered through surgical gauze and centrifuged at $400 \times g\left(10 \mathrm{~min}, 4^{\circ} \mathrm{C}\right)$. If necessary, erythrocytes were lysed by hypo-osmotic shock. The pellet was resuspended in Gey balanced salt solution (GBSS), pH 7.4 and alveolar macrophages were purified by density gradient centrifugation $(400 \times g, 30$ $\min , 4^{\circ} \mathrm{C}$ ) using Ficoll-Isopaque (Nycomed, Oslo, Norway). After extensive washing, more than $95 \%$ of the isolated cell suspension consisted of alveolar macrophages as judged by May-Grünwald-Giemsa staining. Viability of the cells was assessed by dye exclusion using Trypan blue and alveolar macrophage suspensions with a viability exceeding $95 \%$ were used for the experiments.

\subsection{Incubation procedure}

$1 \mathrm{ml}$ samples of alveolar macrophages $\left(10^{6}\right)$ were incubated in GBSS at $37^{\circ} \mathrm{C}$ in the presence of $400 \mu \mathrm{M}$ IBMX (3-isobutyl-1-methylxanthine, Janssen Chimica, Beerse, Belgium) with histamine (Pharmacy Department, Dijkzigt Hospital, Rotterdam, Netherlands), prostaglandin $\mathrm{E}_{2}\left(\mathrm{PGE}_{2}\right)$, prostacyclin $\left(\mathrm{PGI}_{2}\right)$, platelet activating factor (PAF), salbutamol or isoprenaline (all from Sigma, St. Louis, MO, USA) dissolved in GBSS buffer. In some experiments cell suspensions were preincubated for $10 \mathrm{~min}$ with propranolol (Ciba-Geigy, Basel, Switzerland), cimetidine (Sigma, St. Louis, MO, USA) or mepyramine (Rhône-Poulenc, Paris, France). Following a $15 \mathrm{~min}$ incubation, cells were spinned down and resuspended in $150 \mu \mathrm{l}$ Tris- $\mathrm{HCl}$ buffer $(\mathrm{pH}$ 7.4) and boiled for $3 \mathrm{~min}$. Cellular content of cAMP was determined by radioimmunoassay using $\left[{ }^{3} \mathrm{H}\right] \mathrm{cAMP}$ (Amersham, Amersham, UK) and a high-affinity binding protein as described previously (Bonta et al., 1984).

\subsection{Statistical analysis}

Data are expressed as means \pm S.E.M. Statistical significance was evaluated by the unpaired MannWhitney $U$ test. A $P$ value of $<0.05$ was considered significant. 


\section{Results}

Table 1 shows the cellular differentiation of the BAL fluids from the three different groups of subjects (controls, COPD patients and asthmatics). Alveolar macrophages make up the majority of the recovered cells $(91.5-95.5 \%)$ with a marked decrease in the percentage in the BAL fluids from COPD patients and an increase in the number of lymphocytes, eosinophils and neutrophils.

Basal cAMP levels were significantly higher (plus $42 \%$ ) in alveolar macrophages from COPD patients as compared to control alveolar macrophages, while alveolar macrophages from (two) asthmatics showed the same level as controls (cf. table 2).

The stimulatory effects of inflammatory mediators $\left(\mathrm{PGE}_{2}, \mathrm{PGI}_{2}, \mathrm{PAF}\right.$ and histamine) and $\beta$-sympathicomimetics (isoprenaline and salbutamol) on cyclic AMP production in different alveolar macrophage populations are depicted in figs. 1 and 2. Prostaglandin $\mathrm{E}_{2}$ and histamine dose-dependently stimulated cAMP
TABLE 1

Cellular differentiation (in percentages) of BAL fluids from controls, COPD patients and asthmatics.

Number of observations in parentheses.

\begin{tabular}{lccc}
\hline & $\begin{array}{l}\text { Controls } \\
(22)\end{array}$ & $\begin{array}{l}\text { COPD } \\
\text { patients (12) }\end{array}$ & \multicolumn{1}{l}{$\begin{array}{l}\text { Asthmatics } \\
(2)\end{array}$} \\
\hline Macrophages & $95.5 \pm 0.6$ & $87.2 \pm 3.6^{*}$ & $91.5 \pm 0.5$ \\
Lymphocytes & $2.3 \pm 0.4$ & $4.3 \pm 0.6^{*}$ & $3.5 \pm 2.5$ \\
Eosinophils & $0.6 \pm 0.2$ & $1.9 \pm 0.7^{*}$ & $3.2 \pm 2.5$ \\
Neutrophils & $0.3 \pm 0.1$ & $4.8 \pm 2.8^{*}$ & $0.4 \pm 0.9$ \\
Mononuclear cells ${ }^{\text {a }}$ & $1.3 \pm 0.8$ & $1.8 \pm 0.6$ & $1.4 \pm 0.7$ \\
\hline
\end{tabular}

${ }^{\mathrm{a}}$ Other than macrophages or lymphocytes.

* $\mathrm{P}<0.05$ as compared to controls.

production in the three alveolar macrophage populations, though less effectively in alveolar macrophages from COPD patients and asthmatics (cf. figs. 1a and $1 d$ respectively). Using $\mathrm{PGI}_{2}$, no difference in adenylyl cyclase responsiveness among the three different alveolar macrophage populations (cf. fig. 1b) was observed.
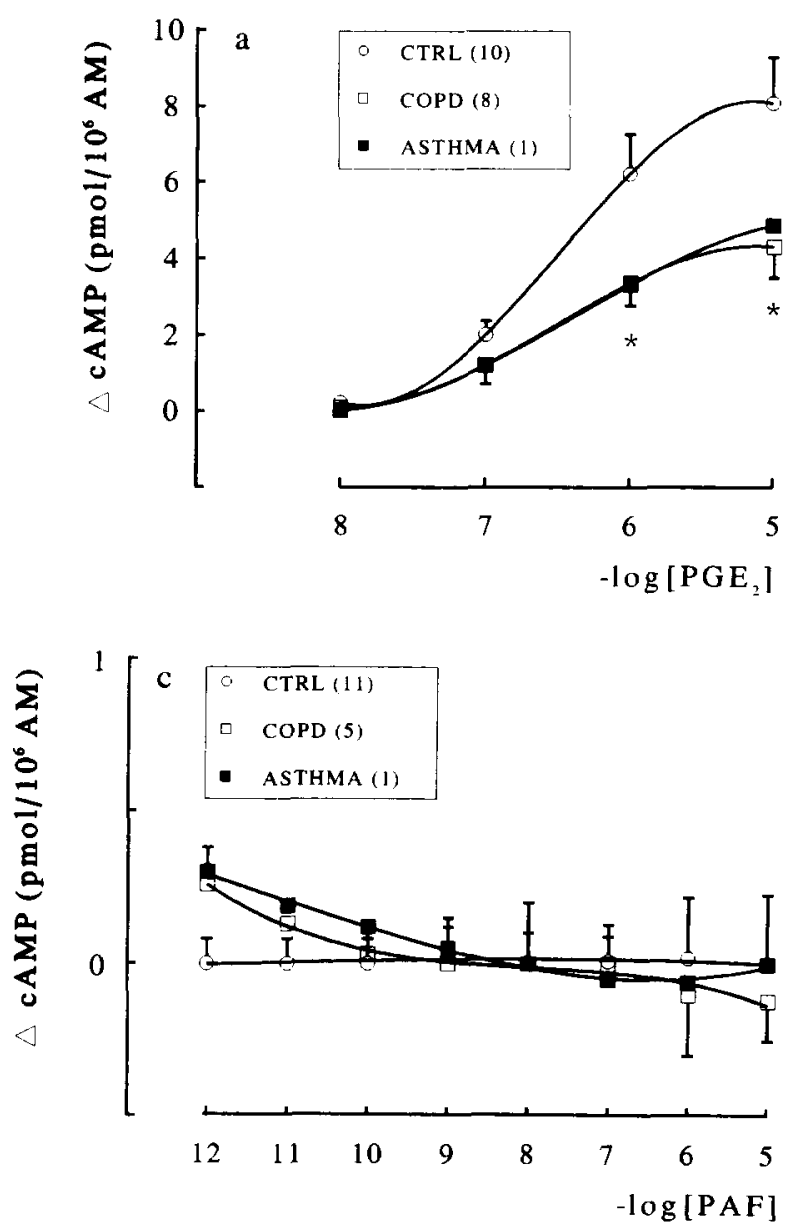
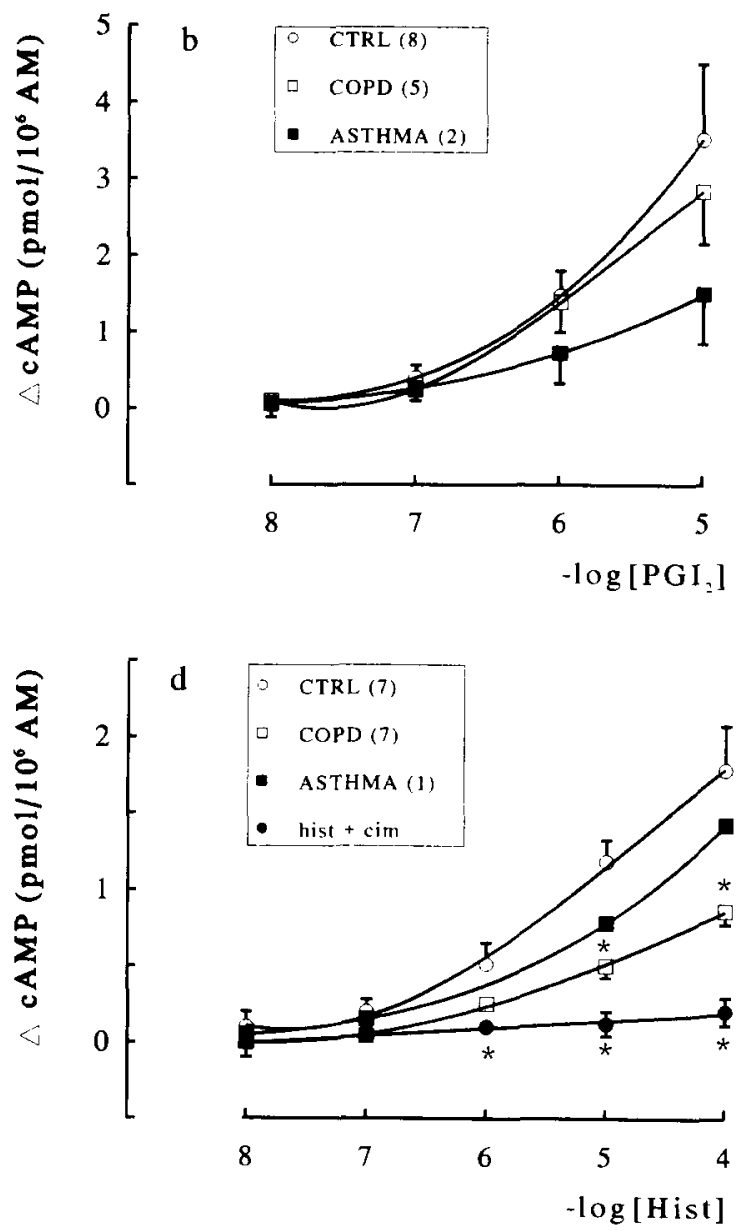

Fig. 1. Cyclic AMP production in alveolar macrophages (AM) from control subjects (CTRL, open circles), COPD patients (COPD, open squares) and asthmatics (ASTHMA, closed squares) following a $15 \mathrm{~min}$ incubation with the inflammatory mediators PGE $_{2}$ (a), PGI $_{2}$ (b), PAF (c), and histamine (d) in the presence of $400 \mu \mathrm{M}$ IBMX. Prior to incubation with histamine, control alveolar macrophages were incubated with the $\mathrm{H}_{2}$-selective antagonist cimetidine $10^{-5} \mathrm{M}$ (panel d, closed circles). Number of duplicate observations in parentheses. Data are expressed as mean absolute increase above basal cAMP level \pm S.E.M. (pmol $/ 10^{6}$ alveolar macrophages). ${ }^{*} \mathrm{P}<0.05$ as compared to controls. 


\section{TABLE 2}

Basal cAMP levels in alveolar macrophages from controls, COPD patients and asthmatics.

Data are expressed as mean \pm S.E.M. (pmol $/ 10^{6}$ alveolar macrophages) from 22 (controls), 12 (COPD patients) and two (asthmatics) duplicate experiments.

\begin{tabular}{ll}
\hline & cAMP (pmol $/ 10^{6}$ alveolar macrophages) \\
\hline Controls & $1.63 \pm 0.11$ \\
COPD patients & $2.31 \pm 0.28 *$ \\
Asthmatics & $1.57 \pm 0.93$ \\
\hline
\end{tabular}

${ }^{*} \mathrm{P}<0.05$ as compared to controls.

The lipid mediator PAF does not affect cAMP levels in alveolar macrophages (cf. fig. 1c). At the lowest concentration $\left(10^{-12} \mathrm{M}\right)$, however, PAF tends to enhance cAMP production in alveolar macrophages from COPD patients $(+15 \%)$ and asthmatics $(+17 \%)$.

The adenylyl cyclase responsiveness to isoprenaline and salbutamol shows similar results as the response of the inflammatory mediators. The non-selective $\beta$ adrenoceptor agonist isoprenaline enhances cAMP levels in all three alveolar macrophage populations with the same potency (cf. fig. $2 \mathrm{a}$ ), whereas the response to the $\beta_{2}$-selective adrenoceptor agonist salbutamol is largely reduced in alveolar macrophages from COPD patients and asthmatics (cf. fig. 2b).

The stimulatory effects of isoprenaline and salbutamol on cAMP production were completely blocked by propranolol $10^{-5} \mathrm{M}$ (cf. figs. $2 \mathrm{a}$ and $2 \mathrm{~b}$ ). Considering the high potency of salbutamol, $\beta_{2}$-adrenoceptors appear to mediate this action. The histaminergic effect is attained by stimulation of histamine $\mathrm{H}_{2}$ receptors as the $\mathrm{H}_{2}$-selective antagonist cimetidine $\left(10^{-5} \mathrm{M}\right) \mathrm{com}$ pletely reversed the effect (cf. fig. 1d) while the $\mathrm{H}_{1}$ - selective antagonist mepyramine $\left(10^{-5} \mathrm{M}\right)$ was in this respect not effective (results not shown).

It should be mentioned that due to the poor availability of alveolar macrophages from asthmatics, we were not able to determine the adenylyl cyclase responsiveness more adequately in this alveolar macrophage population.

\section{Discussion}

Recently, we have shown in human alveolar macrophages that the $\boldsymbol{\beta}_{2}$-adrenergic agonist salbutamol and the phosphodiesterase inhibitor IBMX inhibited $\mathrm{PGE}_{2}$ release and stimulated leukotriene $\mathrm{B}_{4}\left(\mathrm{LTB}_{4}\right)$ secretion via enhancement of intracellular cAMP levels (Beusenberg et al., submitted for publication). Hence, we were interested to determine whether inflammatory mediators and $\beta$ sympathicomimetics showed the same potency to stimulate cAMP production in alveolar macrophages from controls, COPD patients and asthmatics.

Cellular composition of BAL fluids from the three groups of subjects differed largely with respect to the number of alveolar macrophages, eosinophils, neutrophils and lymphocytes which is in accordance with previous results. Thus, an increase in the number of predominantly eosinophils in BAL fluids from asthmatics has been reported by Wardlaw et al. (1988) and Tomioka et al. (1984) wherease in BAL fluids from COPD patients an increase of neutrophils has been reported (Martin et al., 1985). The increase in the number of lymphocytes in COPD patients and asthmatics (both groups consisting of non-allergic subjects)
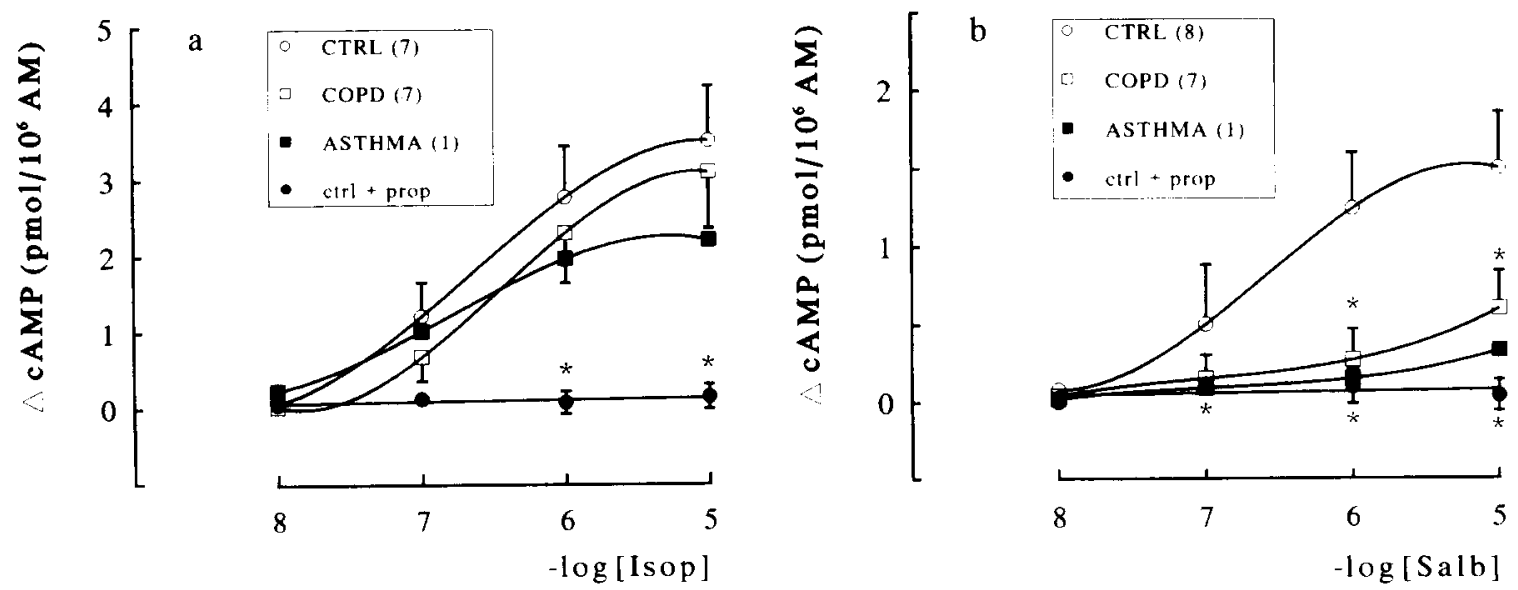

Fig. 2. Cyclic AMP production in alveolar macrophages (AM) from control subjects (CTRL, open circles), COPD patients (COPD, open squares) and asthmatics (ASTHMA, closed squares) following a $15 \mathrm{~min}$ incubation with the $\beta$-adrenoceptor agonists isoprenaline (Isop, panel a) and salbutamol (Salb, panel b) in the presence of $400 \mu \mathrm{M}$ IBMX. Prior to incubation with the agonists, control alveolar macrophages were incubated with the non-selective $\beta$-adrenoceptor antagonist propranolol (prop, $10^{-5} \mathrm{M}$, closed circles). Number of duplicate observations in parentheses. Data are expressed as mean absolute increase above basal cAMP level \pm S.E.M. (pmol $/ 10^{6}$ alveolar macrophages). ${ }^{*} \mathrm{P}<0.05$ as compared to controls. 
observed by us and others (Gonzalez et al., 1987; Metzger et al., 1987) suggests that these cells, besides alveolar macrophages, eosinophils and neutrophils, may play an important role in pulmonary inflammation.

The present results show that initial basal cAMP levels differed largely between the alveolar macrophage populations. Alveolar macrophages from COPD patients contained some $40 \%$ more cAMP than control alveolar macrophages whereas basal cAMP levels in alveolar macrophages from asthmatics showed no differences compared to controls.

For different reasons, it is difficult to interpret our data on basal cAMP in alveolar macrophages from asthmatics with functional parameters as conflicting data have been reported. Thus, while some reports indicate altered functional activity (e.g. chemiluminescence and arachidonic acid metabolism) in alveolar macrophages from asthmatics (Godard et al., 1982; Cluzel et al., 1987; Damon et al., 1989), others have reported similar results between alveolar macrophages from asthmatics and controls (Balter et al., 1988). In addition, our results were merely based on two asthmatics (which suggested no differences in basal cAMP levels). Whether functional activity of alveolar macrophages from asthmatics indeed differs from controls remains to be established.

One can only speculate about the origin of the enhanced basal cAMP levels in alveolar macrophages from COPD patients. Possibly, the persistent local inflammatory environment generates various mediators, like $\mathrm{PGE}_{2}, \mathrm{PGI}_{2}$ and histamine which stimulate cAMP production in alveolar macrophages located in the alveolar compartment. Like in other tissues and cells (Remold-O'Donell, 1974; Meurs et al., 1985), such continuous exposure of alveolar macrophages to inflammatory mediators, which may stimulate adenylyl cyclase, will ultimately induce a desensitization of the stimulatory receptors. Consequently, alveolar macrophages will become less susceptible to respond to these inflammatory substances. The present data on the diminished responsiveness of the adenylyl cyclasecoupled signal transduction system to various mediators and drugs suggest a heterologous desensitization phenomenon. The differences in potency between the $\beta$-adrenoceptor agonists isoprenaline and salbutamol to stimulate adenylyl cyclase is in accordance with previous results. Using guinea pig alveolar macrophages, we suggested that the observed differences are probably due to the partial agonistic effect of salbutamol (Beusenberg et al., 1989).

The few data on alveolar macrophages from asthmatics presented here point to a similar desensitization of the adenylyl cyclase system in alveolar macrophages, suggesting that asthma shares some common immunoregulatory- and inflammatory-related mechanisms with COPD.
Within the pathophysiology of asthma and COPD, data on the phenomenon of desensitization in pulmonary cells are limited and have been confined to mainly bronchial smooth muscles and blood leukocytes. It is suggested that diminished $\beta$-adrenoceptor function in asthmatics is probably a consequence of the active disease state (following allergen challenge) rather than an intrinsic component of asthma (reviewed by Nijkamp and Henricks, 1990). In the present report, however, we present evidence that a general (including $\beta$-adrenoceptor) dysfunction of the adenylyl cyclase system in alveolar macrophages, an important cellular component within the pulmonary compartment, is a general and intrinsic feature of pulmonary inflammation associated with asthma and COPD.

Physiologically, the impaired responsiveness of the adenylyl cyclase system to stimulatory agents in alveolar macrophages from COPD patients and asthmatics would implicate that cellular functions of the alveolar macrophages which are affected by alterations in cAMP levels (like oxygen radical and enzyme production) are less susceptible to modulation by external factors. Whether this renders the alveolar macrophages more sensitive to external modulation via mechanisms distinct from the adenylyl cyclase pathway remains to be investigated.

\section{Acknowledgements}

The authors wish to thank Mrs. J.M.E. van Schaik and the residents of the Departments of Pulmonology at the Dijkzigt University Hospital, Haven Hospital and St. Clara Hospital for their excellent technical expertise. This study was financially supported by the Netherlands Asthma Foundation (NAF).

\section{References}

Arnoux, B., D. Duval and J. Benveniste, 1980, Release of platelet activating factor (PAF-acether) from alveolar macrophages by the calcium ionophore A23187 and phagocytosis, Eur. J. Clin. Invest. $10,437$.

Arnoux, B., M. Joseph, N.H. Simoes, A.B. Tonnel, P. Duroux, A. Capron and J. Benveniste, 1987, Antigenic release of PAF-acether and $\beta$-glucuronidase from alveolar macrophages of asthmatics, Bull. Eur. Physiopathol. Respir. 23, 119.

Balter, M.S., W.L. Eschenbacher and M. Peters-Golden, 1988, Arachidonic acid metabolism in cultured alveolar macrophages from normal, atopic, and asthmatic subjects, Am. Rev. Respir. Dis. 138, 1134.

Barnes, P.J., 1987, Inflammatory mediator receptors and asthma, Am. Rev. Respir. Dis. 135, S26.

Beusenberg, F.D., M.J.P. Adolfs, J.M.E. van Schaik, J.G.C. van Amsterdam and I.L. Bonta, 1989, Antigen challenge modifies the cyclic AMP response of inflammatory mediators and $\beta$-adrenergic drugs in alveolar macrophages, Eur. J. Pharmacol. 174, 33.

Bonta, I.L. and M.J. Parnham, 1982, Immunomodulatory-antiinflammatory functions of E-type prostaglandins. Minireview with 
emphasis on macrophage-mediated effects, Int. J. Immunopharmacol. 4, 103.

Bonta, I.L., M.J.P. Adolfs and M.W.J.A. Fieren, 1984, Cyclic AMP levels and their regulation by prostaglandins in peritoneal macrophages of rats and humans, Int. J. Immunopharmacol. 6, 547.

Chavis, C., P. Godard, F.B. Michel, A. Crastes de Paulet and M. Damon, 1991, Sulfidopeptide leukotrienes contribute to human alveolar macrophage activation in asthma, Prostaglandin Leukotriene Ess. Fatty Acids 42, 95.

Chung, K.F., 1990, Role of inflammation in the hyperreactivity of the airways in asthma, Thorax 41, 657.

Cluzel, M., M. Damon, P. Chanez, J. Bousquet, A. Crastes de Paulet, F.B. Michel and P. Godard, 1987, Enhanced alveolar cell luminol-dependent chemiluminescence in asthma, J. Allergy Clin. Immunol. 80, 195.

Damon, M., C. Chavis, J.P. Daures, A. Crastes de Paulet, F.B. Michel and P. Godard, 1989, Increased generation of the arachidonic acid metabolites $\mathrm{LTB}_{4}$ and 5-HETE by human alveolar macrophages in patients with asthma: effect in vitro of nedocromil sodium, Eur. Respir. J. 2, 202.

Fels, A.O. and Z.A. Cohn, 1986, The alveolar macrophage, J. Appl. Physiol. 60, 353.

Fels, A.O., N.A. Pawlowski, E.B. Cramer, T.K.C. King, Z.A. Cohn and W.A. Scott, 1982, Human alveolar macrophages produce leukotriene $\mathrm{B}_{4}$, Proc. Natl. Acad. Sci. USA 79, 7866.

Finney, M.J.B., J.A. Karlsson and C.G.A. Persson, 1985, Effects of bronchoconstrictors and bronchodilators on a novel human small airway preparation, Br. J. Pharmacol. 85, 28.

Gardiner, P.J., 1975, The effects of some natural prostaglandins on isolated human circular bronchial muscle, Prostaglandins 10, 607.

Godard, P., J. Chaintreuil, M. Damon, M. Coupe, O. Flandre, A. Crastes de Paulet and F.B. Michel, 1982, Functional assessment of alveolar macrophages: comparison of cells from asthmatics and normal subjects, J. Allergy Clin. Immunol. 70, 88.

Goetzl, E.J. and W.C. Pickett, 1981, Novel structural determinants of the human neutrophil chemotactic activity of leukotriene $\mathbf{B}_{4}, \mathrm{~J}$. Exp. Med. 153, 482.

Gonzalez, C., P. Diaz, F. Galleguillos, P. Ancic, O. Cromwell and A.B. Kay, 1987, Allergen induced recruitement of bronchoalveolar T-helper (OKT4) and T-suppressor (OKT8) cells in asthma. Relative increases in OKT 8 cells in single early responders compared with those in late-phase responders, Am. Rev. Respir. Dis. 136,600 .

Hannah, C.J., M.K. Bach, M.D. Pare and R.R. Schellenberg, 1981, Slow-reacting substances (leukotrienes) contract human airway and pulmonary vascular smooth muscle in vitro, Nature $290,343$.

Kelley, J., 1990, Cytokines of the lung, Am. Rev. Respir. Dis. 141, 765

MacDermot, J., C.R. Kelsey, K.A. Wadell, R. Richmond, R.K. Knight, P.J. Cole, C.T. Dollery and D.N. Blair, 1984, Synthesis of leukotriene $\mathrm{B}_{4}$ and prostanoids by human alveolar macrophages: analysis by gas chromatography/mass spectrometry. Prostaglandins 27, 163.

Martin, T.R., L.C. Altman, R.K. Albert and W.R. Henderson, 1984, Leukotriene $\mathrm{B}_{4}$ production by human alveolar macrophages: a potential mechanism for amplifying inflammation in the lung, Am. Rev. Respir. Dis. 129, 106.

Martin, T.R., G. Raghu, R.J. Maunder and S.C. Springmeyer, 1985, The effects of chronic bronchitis and chronic airflow obstruction in lung cell populations recovered by bronchoalveolar lavage, Am. Rev. Respir. Dis. 132, 254.

Metzger, W.J., D. Zavala, H.B. Richerson, P. Moseley, P. Iwamoto, M.M. Monick, K. Sjoerdsma and G.W. Hunninghake, 1987, Local allergen challenge and bronchoalveolar lavage of allergic asthmatic lungs. Description of the model and local airway inflammation, Am. Rev. Respir. Dis. 135, 433.

Meurs, H., G.H. Koëter, H.F. Kaufmann, A. Timmermans, B. Folkers and $\mathrm{K}$. de Vries, 1985, Reduced adenylate cyclase responsiveness to histamine in lymphocyte membranes of allergic asthmatic patients after allergen challenge, Int. Arch. Allergy Appl. Immunol. 76, 256.

Morley, J., M.A. Bray, R.W. Jones, D.H. Nugteren and D.A. van Doys, 1979, Prostaglandin and thromboxane production by human and guinea-pig macrophages and leukocytes, Prostaglandins $17,730$.

Nijkamp, F.P. and P.A.J. Henricks, 1990, Receptors in airways. Beta-adrenoceptors in lung inflammation, Am. Rev. Respir. Dis. 141, S145.

Persson, C.G.A., 1988, Plasma exudation in asthma, Lung 166, 1.

Remold-O'Donell, E., 1974, Stimulation of desensitization of macrophage adenylate cyclase by prostaglandins and catecholamines, J. Biol. Chem. 11, 3615.

Sibille, Y. and H.Y. Reynolds, 1989, Macrophages and polymorphonuclear neutrophils in lung defense and injury, Am. Rev. Respir. Dis. 141, 471.

Takemura, R. and Z. Werb, 1984, Secretory products of macrophages and their physiological functions, Am. J. Physiol. 246, C1.

Tomioka, M., S. Ida, D. Yuziko, T. Ishihara and T. Takishima, 1984, Mast cells in bronchoalveolar lumen of patients with bronchial asthma, Am. Rev. Respir. Dis. 129, 1000.

Tonnel, A.B., P.H. Gossett, M. Joseph, P. Lassalle, J.P. Dassaint and A. Capron, 1986, Alveolar macrophage and its participation in inflammatory processes of allergic asthma, Bull. Eur. Physiopathol. Respir. 22, 70.

Wardlaw, A.J., R. Moqbel, O. Cromwell and A.B. Kay, 1986, Platelet activating factor. A potent chemotactic and chemokinetic factor for human eosinophils, J. Clin. Invest. 78, 1701.

Wardlaw, A.J., S. Dunnette, G.J. Gleich, J.V. Collins and A.B. Kay, 1988, Eosinophils and mast cells in bronchoalveolar lavage in mild asthma: relationship to bronchial hyperreactivity, Am. Rev. Respir. Dis. 137, 62. 